\title{
Demonstration of Jackhammer Incorporating Depleted Uranium
} \author{
L.E. Fischer, R.W. Hoard, D. L. Carter, M.D. Saculla, G.V.
Wilson
}

\section{April 1, 2000}

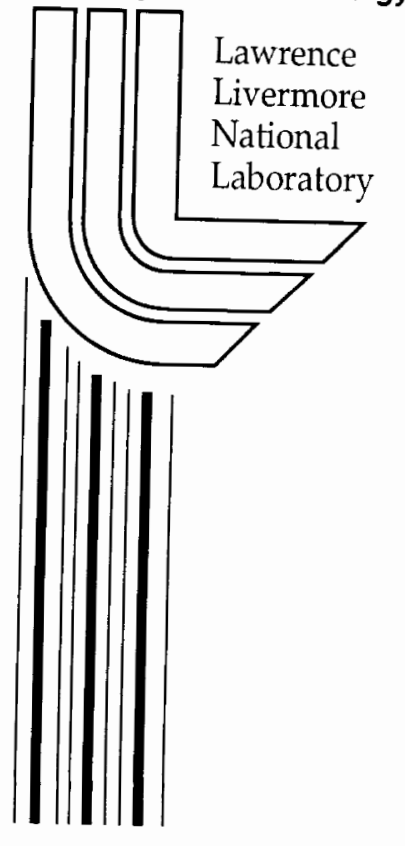





\section{DISCLAIMER}

This document was prepared as an account of work sponsored by an agency of the United States Government. Neither the United States Government nor the University of California nor any of their employees, makes any warranty, express or implied, or assumes any legal liability or responsibility for the accuracy, completeness, or usefulness of any information, apparatus, product, or process disclosed, or represents that its use would not infringe privately owned rights. Reference herein to any specific commercial product, process, or service by trade name, trademark, manufacturer, or otherwise, does not necessarily constitute or imply its endorsement, recommendation, or favoring by the United States Government or the University of California. The views and opinions of authors expressed herein do not necessarily state or reflect those of the United States Government or the University of California, and shall not be used for advertising or product endorsement purposes.

This work was performed under the auspices of the U.S. Department of Energy by the University of California, Lawrence Livermore National Laboratory under Contract No. W-7405-Eng-48.

This report has been reproduced directly from the best available copy.

Available electronically at http://www.doe.gov/bridge

Available for a processing fee to U.S. Department of Energy and its contractors in paper from

U.S. Department of Energy

Office of Scientific and Technical Information

P.O. Box 62

Oak Ridge, TN 37831-0062

Telephone: (865) 576-8401

Facsimile: (865) 576-5728

E-mail: reports@adonis.osti.gov

Available for the sale to the public from

U.S. Department of Commerce

National Technical Information Service 5285 Port Royal Road Springfield, VA 22161

Telephone: (800) 553-6847

Facsimile: (703) 605-6900

E-mail: orders@ntis.fedworld.gov

Online ordering: http://www.ntis.gov/ordering.htm

\section{OR}

Lawrence Livermore National Laboratory

Technical Information Department's Digital Library

http://www.llnl.gov/tid/Library.html 

ICRL-ID-

\section{Demonstration of Jackhammer Incorporating Depleted Uranium}

Manuscript Date: April 2000

Larry E. Fischer, Ronald W. Hoard, David L. Carter, Michael D. Saculla, Geoffrey V. Wilson*

*Summer Student, 1998/1999 



\section{CONTENTS}

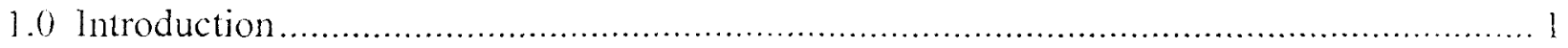

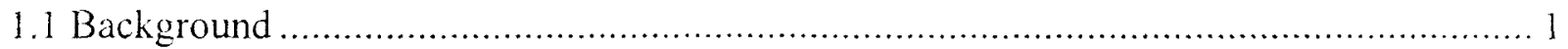

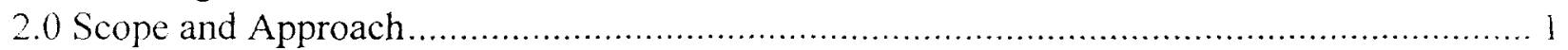

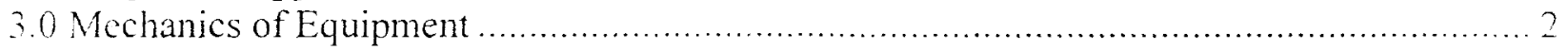

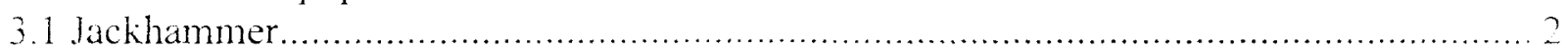

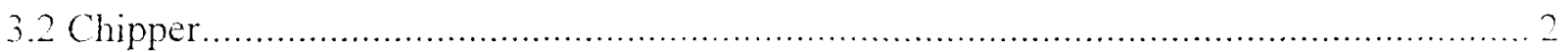

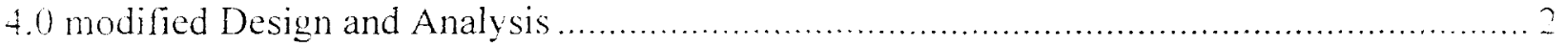

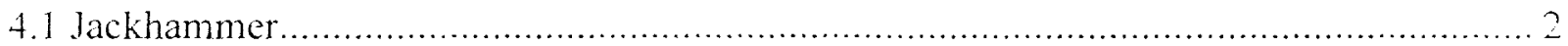

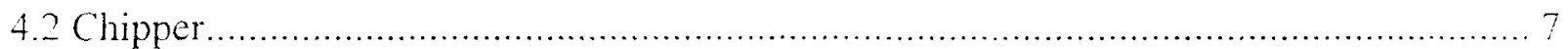

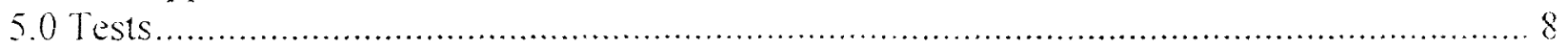

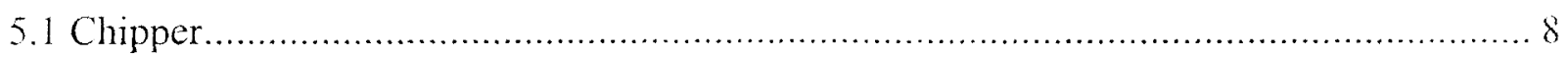

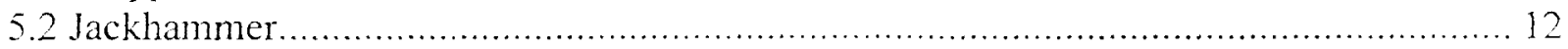

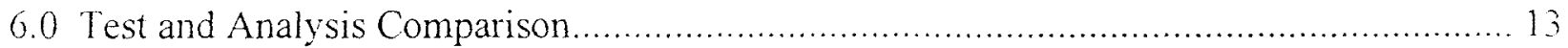

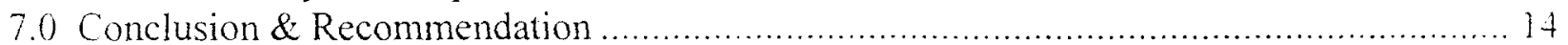

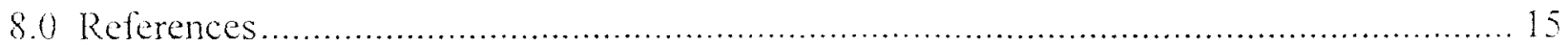




\section{FIGURES}

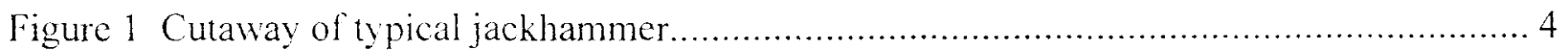

Figure 2 Modified piston/striker bar design ............................................................. 5

Figure 3 Velocity ratio as function of product of density and Young's modulus ratio normalized

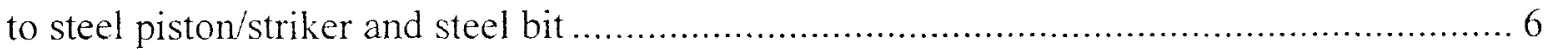

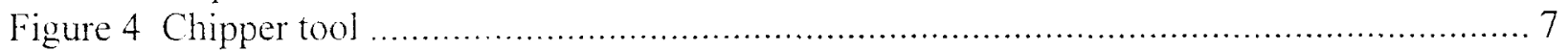

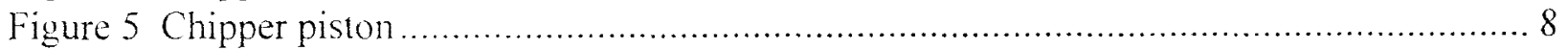

Figure 6 Spring extension versus time for chipper tool ............................................. 10

\section{TABLES}

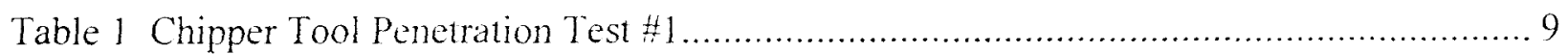

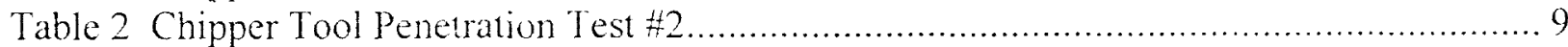

Table 3 Chipper Tool Displacement/Force Tests ............................................... 11

Table 4 Bit Velocity versus Time for Chipper Tools ............................................. 11

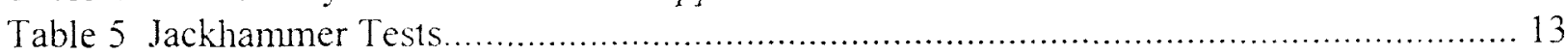




\subsection{INTRODUCTION}

\subsection{Background}

The Unied States Government currenty has an abundance of depleted uranium (DU). This surplus of about 1 billion pounds is the result of an enrichment process using gaseous diffusion 10 produce enriched and depleted uranium. The enriched uranium has been used primarily for either nuclear weapons for the military or nuclear fuel for the commercial power industry. Most of the depleted uranium remains at the enrichment process plants in the form of depleted uranium hexafluoride (DUF 6 ). The Department of Energy (DOE) recently began a study to identify possible commercial applications for the surplus material.

One of these potential applications is to use the DU in high-density strikers/hammers in pneumatically driven tools, such as jack hammers and piledrivers to improve their impulse performance. The use of DU could potentially increase tunneling velocity and excavation into target materials with improved efficiency.

This repont describes the efforts undertaken to analyze the particulars of using DU in two specific striking applications: the jackhammer and chipper tool.

\subsection{SCOPE AND APPROACH}

Industry uses many types of impact tools and equipment ranging from small chippers and scalers to medium jackhammers, large pile-drivers, and stamping machines. The effectiveness of an impact tool partially depends on the density of the part that provides the impact energy. The jackhammer and chipper were used to demonstrate increased effectiveness with the increase of material density. A commercially available jackhammer and chipper were modified by replacing their steel pistons with a heavy metal tungsten alloy which has essentially the same density as DU. Although tungsten alloy is much more expensive than DU, it is not radioactive and hence is easier to fabricate and to test. The jackhammer design modifications took into account that DU is radioactive.

A test demonstration was conducted to compare the modified jackhammer and chipper with the original unmodified ones. Test parameters included cutting speed or depth, thickness and hardness of material being cut, and type of cutting tools. Specific effects and overall comfort of the operator were assessed. 


\subsection{VIECHANICS OF EQUIPMENT}

\subsection{Jackhammer}

A jackhammer is a portable oscillating rock drill operated by compressed air. The compressed air provides a pressure behind a piston/striker bar (PSB) and imparts kinetic energy to the PSB. The PSB strikes a tool bit providing it with momentum and energy. The tool bit impacts and penetrates a target material such as concrete. The penetration into the target material depends on the momentum and energy transferred to the target material.

\subsection{Chipper}

The chipper works on the same principle as the jackhammer in that it uses compressed air to accelerate a piston, which impacts a tool bit which then impacts the target material. The primary difference from the jackhammer is that the chipper is a smaller hand held tool and is used for knocking out bolts or chipping into concrete.

\subsection{MODIFIED DESIGN AND ANALYSIS}

\subsection{Jackhammer}

A cutaway illustration of a jackhammer is shown in Figure 1. This specific jackhammer model has an integral PSB which imparts the kinetic energy to the bit or other impacted tool. The initial DU design modifies only the integral PSB. The striker bar portion is bored out, leaving some cladding material in order to completely encapsulate the DU. The initial design used a press fit cap to hold the tungsten alloy bar (substitute for DU) in place inside the bored out cavity. The initial design modification increased the piston/striker bar weight by $60 \%$. Buckling and finite element analysis of the bored out bar with the tungsten alloy insert were performed. The analyses showed that the design would not fail for the anticipated loading. During testing, the jackhammer vibration caused the press fit cap assembly to disengage due to knock-on by the tungsten alloy bar against the end of the cavity. The cladding material failed and the testing ended before any significant data was recorded.

A second design was developed that used a cap screw to hold the tungsten alloy bar in place against the end of the cavity. In its final configuration, shown in Figure 2, the cap screw was epoxied in place with a $200 \mathrm{ft}-\mathrm{lb}$ torque to resist vibration forces to loosen it. This design configuration increases the weight by $45 \%$ compared to the unmodified design. A production model design would use an electroless nickel-coated DU bar inside the cavity and would weigh 40-60\% heavier than the unmodified design (References 1-2). If the entire piston/striker bar part were entirely made of DU, the weight increase would be over $140 \%$.

Several analytical models have been developed that describe the motion of the PSB of a pneumatic jackhammer and the forces exerted by the end of the bit during penetration of a target (References 3-8). These models are somewhat complex and in some cases are programmed to execute on a computer. To estimate the effect of using a heavy metal in place of steel in the PSB 
a simplified wo component vibration model was used based on the analyical model presented in reterences.

The initial penetration rate $V_{b}$ of the bit is estimated by

$$
1=\frac{1}{\rho(H A}(F-F)
$$

Where $\rho . c$. A. are the density. wave velocity and area of the bit denoted by the subscript b. The bit forward force is $\mathrm{Fb}$ and the reflected force is Fr. If the target force penetration efficiency is $50 \%$. expression (1) becomes

$$
V_{i}=1.5 V_{c}\left[\frac{\rho_{p} c_{p} A_{i}}{\rho_{p} c_{p} A_{p}+\rho_{n} c_{n} A_{t}}\right]
$$

Where $V o$ is the initial impact velocity of the PSB onto the bit and $\rho, \mathrm{c} A$ are the density, wave velocity and area of the PSB and bit denoted by subscripts $p$ and $b$ respectively.

The ratio (Vr) of the bit velocity for the modified PSB to that of original steel PSB can be estimated by

$$
\mathrm{V}_{\mathrm{r}}=\frac{\mathrm{V}_{b}^{1}}{\mathrm{~V}_{\mathrm{b}}}=\frac{\mathrm{A}_{\mathrm{b}} / \mathrm{A}_{p}}{1+\frac{\rho_{b} C_{b} A_{b}}{\rho_{p}^{1} c_{p}^{1}}}=\frac{\frac{A_{p}}{A_{b}}+1}{\frac{A_{p}}{A_{b}}+\sqrt{\frac{\rho_{p}^{1} E_{p}^{1}}{\rho_{b} E_{b}}}}
$$

In Figure 3 the initial bit velocity ratio is presented as a function of the density, young modulus $(\rho E)$ ratios normalized steel materials for specific bit to PBS area ratios. 


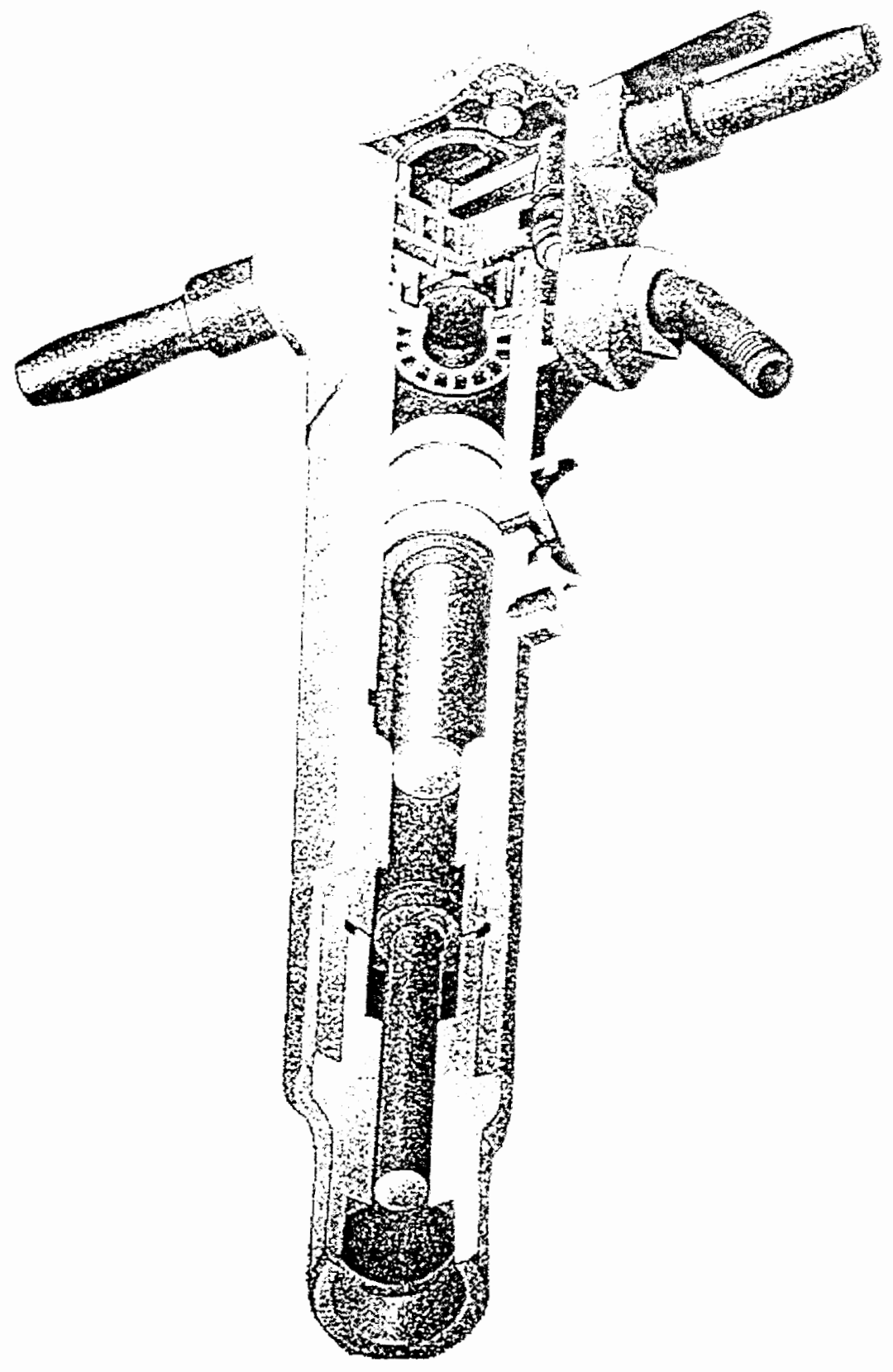

Figure 1 Cutaway of typical jackhammer 


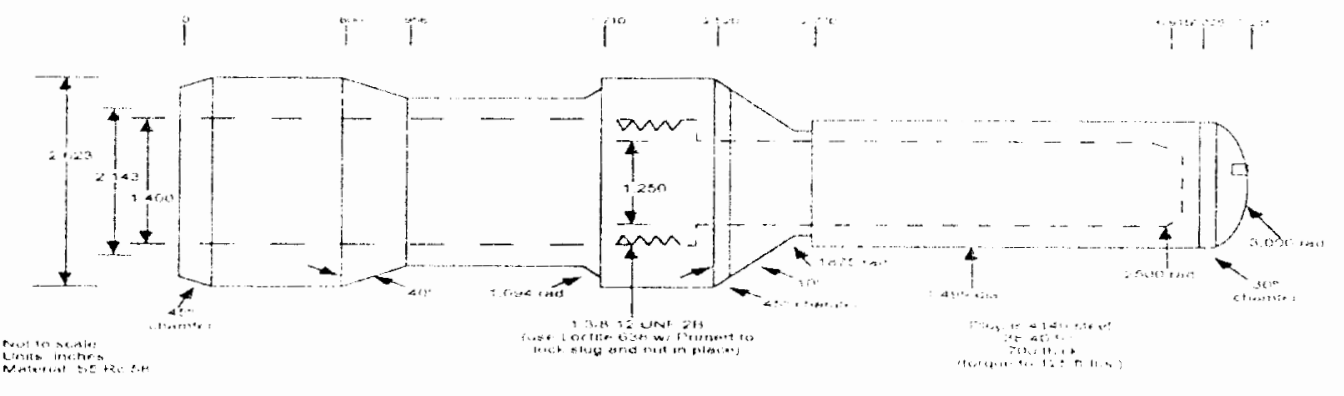

Figure 2 Modified piston/striker bar design 


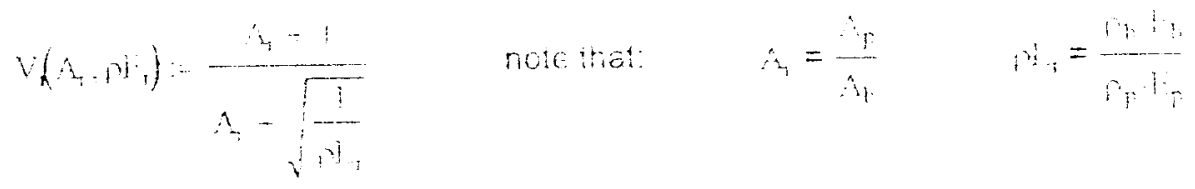

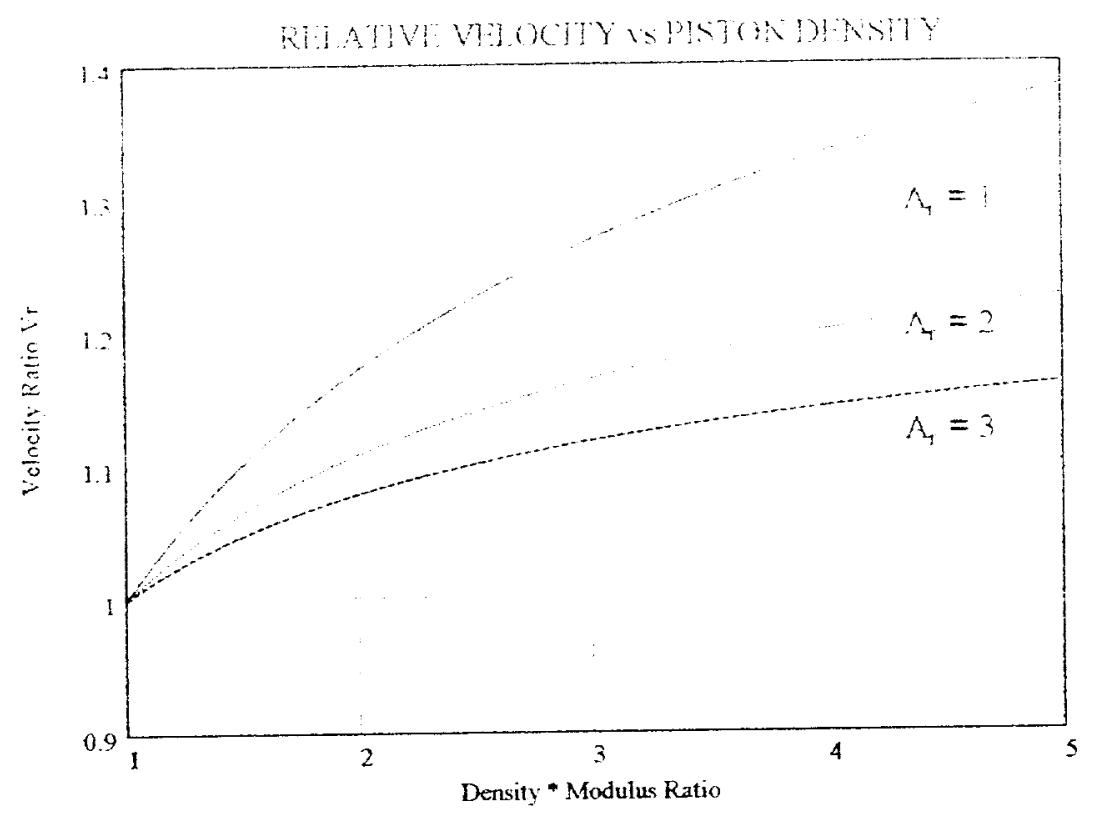

Figure 3 Velocity ratio as function of product of density and Young's modulus ratio normalized to steel piston/striker and steel bit 


\subsection{Chipper}

The chipper 100 was selected to gain experience in operating a lightweight pneumatic impact tool. A model similar to the one in Figure 4 was tested. This particular model uses a beehive or spring retainer to keep the chisel within the tool. The air-driven chipper drives a cylindrical sted piston against a chisel, which impacts the target material. The chipper was modified by replacing the steel piston with a tungsten alloy one. A sketch of the piston is shown in Figure 5.

Originally we planned only to test the chipper $100 \mathrm{l}$ penetration rate or depth into various materials for the two configurations. In operating the chipper tool it was observed that the beehive or spring retainer extended further with the tungsten alloy piston compared to the steel one. There was also a stronger kick or force with the tungsten alloy piston. We decided to measure the spring deflection and spring force to compare the modified tool with the unmodified tool in addition to the penetration tests.

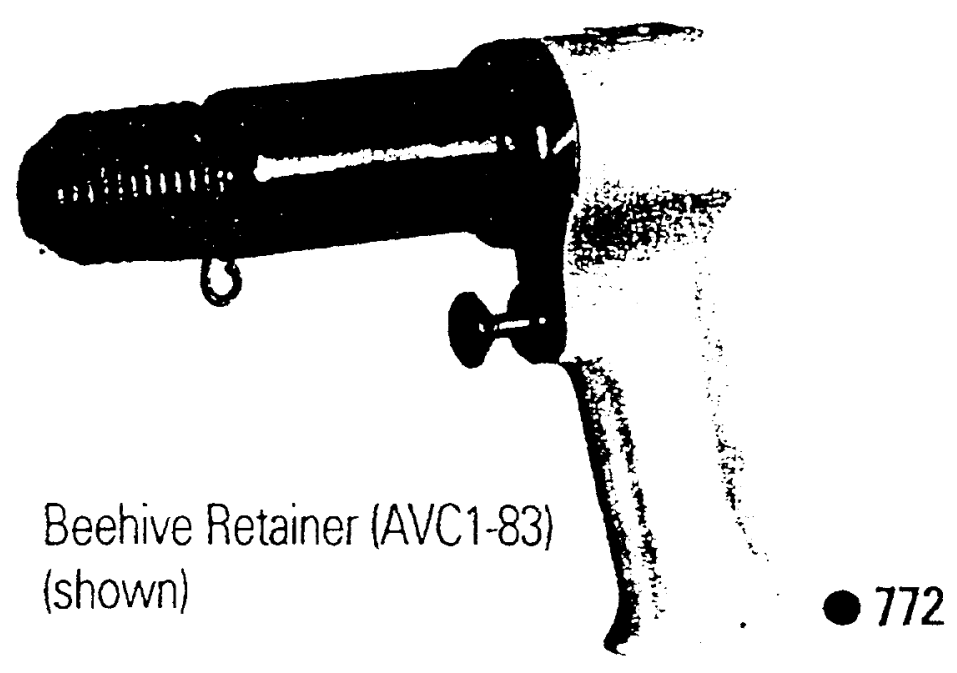

Figure 4 Chipper tool 


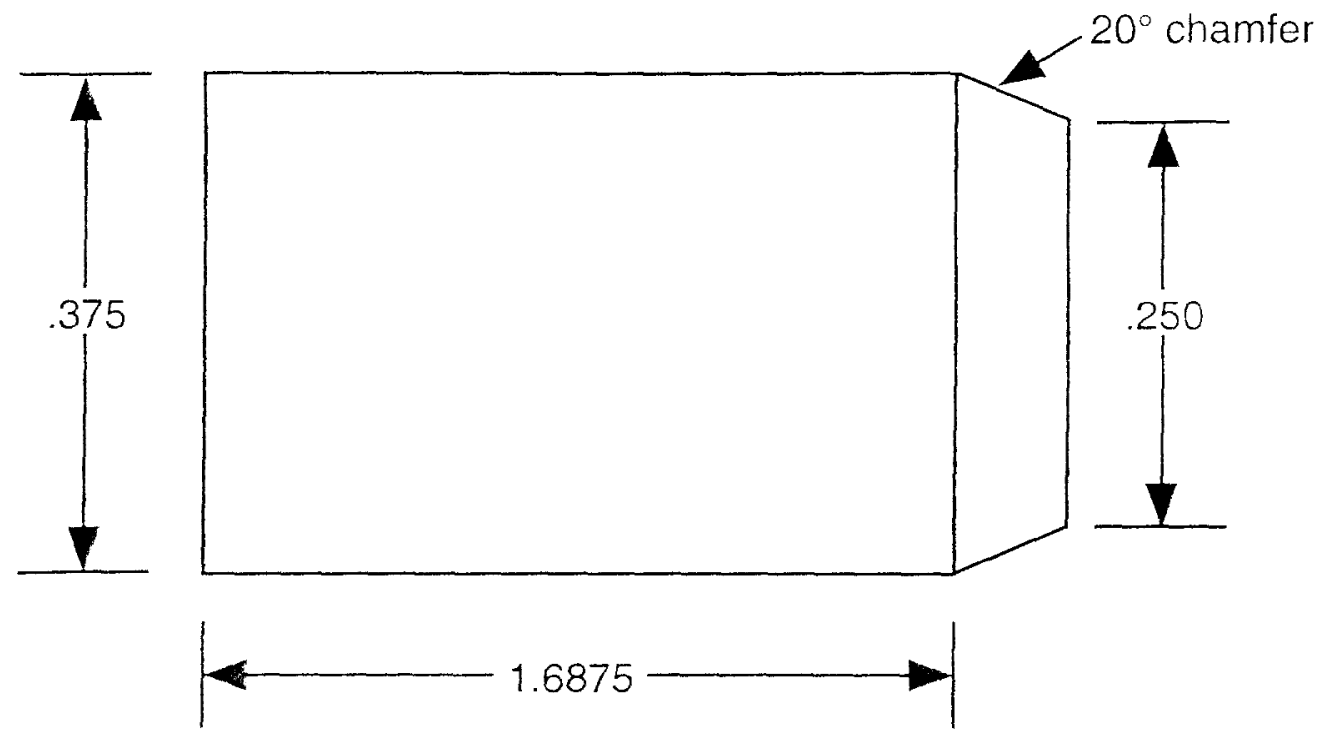

Figure 5 Chipper piston

\subsection{TESTS}

\subsection{Chipper}

The approach for comparing tunneling velocity was to measure the hole depth made by the chipper in an oak wood block using, in one trial, the steel piston, and in another trial, the tungsten alloy piston for the same length of time. The procedure was to apply the chipper chisel against the oak piece, and activate the chipper for a set time period. The depth of the hole was then measured by a micrometer. The same test was then performed on aluminum alloy plate.

The test data are summarized in Tables 1 and 2 for two test sequences.. From the data is appears that the tunneling velocity in the oak is higher for the tungsten alloy piston, but not necessarily higher in the aluminum. The data show large variations for the same test time periods. These variations were initially thought to be due to the variation in wood hardness and plastic hardness of the aluminum. As the tests continued it became apparent that the tunneling velocity was very dependent on the force applied on the chipper tool to hold it against the target material. One operator was able to apply enough force to stall the chipper tool with the steel piston, but could not stall the chipper tool with the tungsten alloy piston. After additional testing and observations it was concluded that the chipper tool with the tungsten alloy piston had a strong force or a "kick" to it, and the retainer spring extended further during operation. It was also concluded that the test penetration results are uncertain. 
Table 1 Chipper Tool Penetration Test \#1

Oak Wood Target Depth (in)

\begin{tabular}{|c|c|c|c|}
\hline Time (sec) & Steel & Tungsten alloy & Percent difference \\
\hline 20 & 0.313 & 0.891 & 180 \\
\hline Aluminum 1060 Bar Depth (in) & \multicolumn{3}{|c|}{} \\
\hline Time (sec) & Steel & Tungsten alloy & Percent difference \\
\hline 30 & 0.012 & 0.026 & 116 \\
\hline 45 & 0.025 & 0.039 & 56 \\
\hline 60 & 0.029 & 0.039 & 34 \\
\hline 75 & 0.034 & 0.039 & 15 \\
\hline
\end{tabular}

Table 2 Chipper Tool Penetration Test \#2

Oak Wood Target Depth (in)

\begin{tabular}{|c|c|c|c|}
\hline Time (sec) & Steel & Tungsten alloy & Percent difference \\
\hline 10 & 0.29 & 0.298 & 2.7 \\
\hline 20 & 0.604 & 0.778 & 29 \\
\hline Aluminum 1060 Bar Depth (in) & \multicolumn{2}{|c|}{} \\
\hline Time (sec) & Steel & Tungsten alloy & Percent difference \\
\hline 15 & 0.029 & 0.019 & -35 \\
\hline 30 & 0.025 & 0.032 & 28 \\
\hline 45 & 0.036 & 0.023 & -37 \\
\hline 60 & 0.03 & 0.04 & 33 \\
\hline
\end{tabular}


It was decided to measure the spring displacement during operation and the spring

dipplacementerce chatacteristics 10 estimate the force transferred to the bit from the piston. The chipper was mounted in a vise to reduce reoil effects. A calibration grid was placed behind the chipper to measure the spring displacement. A video recorder was used 10 measure the spring displacement at the rate of one frame per millisecond. Each run lasted several seconds to reduce startup effects. Three tests were performed with the tungsten alloy piston and two with the stee] piston. The spring exiension versus time for one cycle is shown in Figure 6 . The peat extension of the spring was greane for the tungsten alloy piston. The spring displacement/force chatacteristics were measured and the peat force was calculated for teach of the test runs. The measured peak displacentens and calculated forces are summarized in tabie 3.

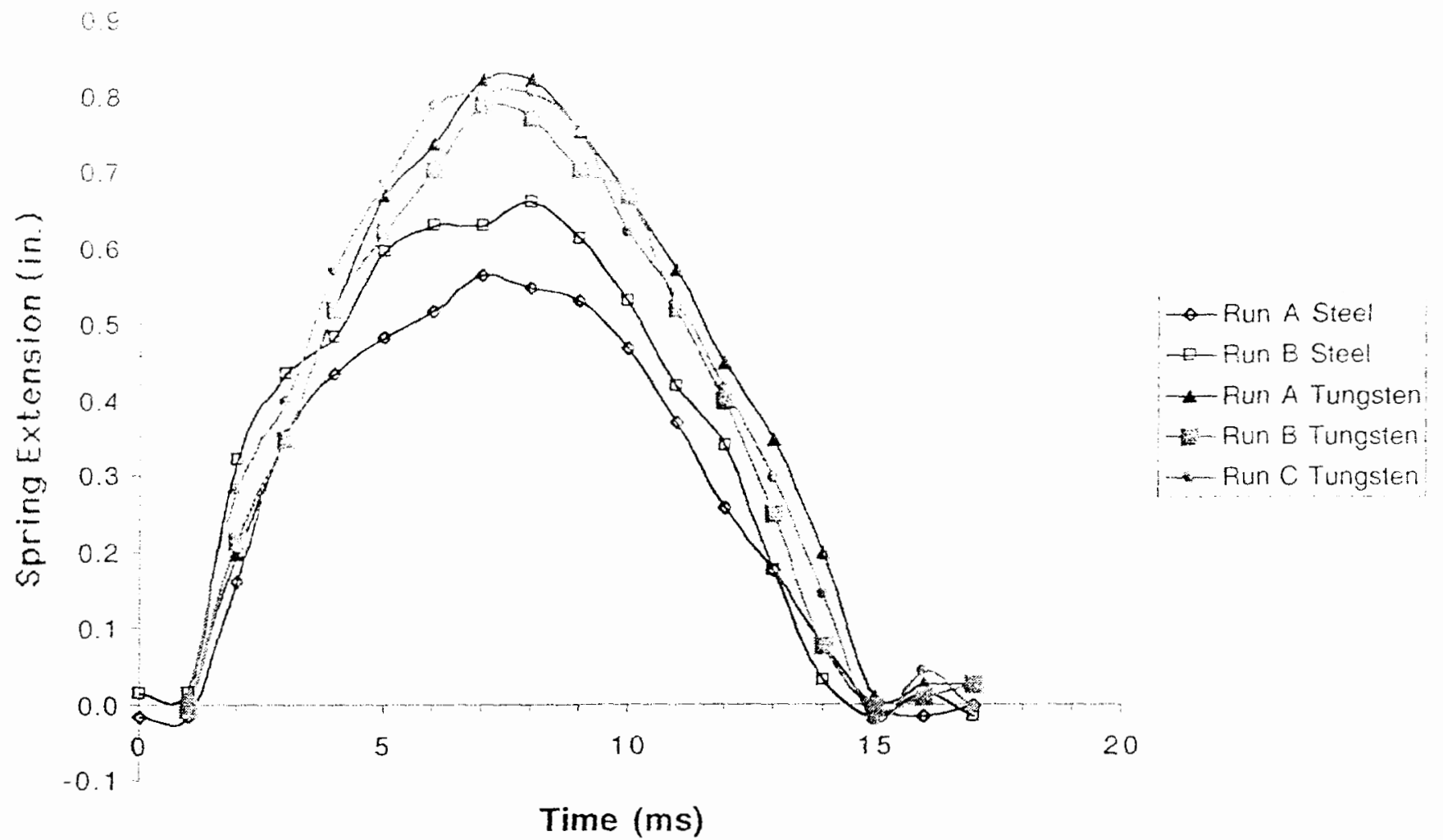

Figure 6 Spring extension versus time for chipper tool 
The average meastred peak displacements for the spring are 0.81 and 0.66 inches for the tumgsten alloy and steel pistons. respectively. The corresponding average peak forces are $42.4 \mathrm{~g}$ and $35.6 \cong$ From the spring force displacement curve it is concluded that the impact energy of the bit is signiticantly higher for the tungsten alloy piston.

The bit velocity versus time was calculated from the spring displacement data and is presented in Table 4. In general the bit velocity for the tungsten alloy piston was higher then that for the steel. The initial velocity was $6 \%$ higher and the rebound impact velocity was $51 \%$ higher. The nomentum of the tungsten alloy piston is significantly higher.

Table 3 Chipper Tool Displacement/Force Tests

\begin{tabular}{|c|c|c|c|c|}
\hline & \multicolumn{2}{|c|}{ Tungsten alloy } & \multicolumn{2}{c|}{ Steel } \\
\hline Run number & $\begin{array}{c}\text { Displacement } \\
\text { peak }\end{array}$ & $\begin{array}{c}\text { Calculated force } \\
\text { (lbf) }\end{array}$ & $\begin{array}{c}\text { Displacement } \\
\text { (in) }\end{array}$ & $\begin{array}{c}\text { Calculated force } \\
\text { (lbf) }\end{array}$ \\
\hline 1 & 0.810 & 42.4 & 0.621 & 34.0 \\
\hline 2 & 0.793 & 41.6 & 0.690 & 37.1 \\
\hline 3 & 0.828 & 43.2 & & \\
\hline $\begin{array}{c}\text { Average } \\
\text { deviation }\end{array}$ & $\mathbf{0 . 8 1 0}$ & $\mathbf{4 2 . 4}$ & $\mathbf{0 . 6 5 6}$ & $\mathbf{3 5 . 6}$ \\
\hline $\begin{array}{c}\text { Coeff. of } \\
\text { veritication }\end{array}$ & 0.018 & 0.80 & 0.049 & 2.19 \\
\hline
\end{tabular}

Table 4 Bit Velocity versus Time for Chipper Tools

\begin{tabular}{|c|c|c|}
\hline & \multicolumn{2}{|c|}{ Velocity } \\
\hline Time & Steel & Tungsten alloy \\
\hline$(\mathrm{msec})$ & (in/sec) & (in/sec) \\
\hline 1 & 197 & 209 \\
\hline 2 & 156 & 185 \\
\hline 3 & 116 & 155 \\
\hline 4 & 78 & 119 \\
\hline 5 & 41 & 79 \\
\hline 6 & 7 & 38 \\
\hline 7 & -23 & -3 \\
\hline 8 & -49 & -42 \\
\hline 9 & -71 & -77 \\
\hline 10 & -87 & -107 \\
\hline 11 & -98 & -129 \\
\hline 12 & -102 & -142 \\
\hline 13 & -98 & -143 \\
\hline 14 & -87 & -132 \\
\hline
\end{tabular}

\footnotetext{
${ }^{1}$ Force $(\mathrm{lbf})=6.52+[44.28 \times$ spring displacement (in) $]$
} 


\subsection{Jackhammer}

The jackhammer tests were conducted using large slabs of concrete that had been excavated from various buildings at the LLNL site. The first tests using the initially modified design abruptly ended when the piston cladding failed. Insufficient data was collected wo make any quantitative conclusions on the performance but prior to the failure the jackhammer with the tungsten alloy piston appeared to cut faster into the concrete slab. The cladding fallure was atributed to knockon between the tungsten alloy insert and the end of the hollow cylindrical cladding after the press fit became loose.

The second design was fabricated and used a cap screw in the place of the press fit plug. The cap screw was torqued to approximately $60 \mathrm{ft}-\mathrm{lbs}$ to lock it into place. The testing went smoothly until the cap screw loosened with the vibration and the cladding failed due to knock-on. A third piston was fabricated which had the cap screw torqued to 200 th-ths and epoxied in place. This final design did not fail and was used 10 cut up a large concrete slab to demonstrate its durability.

The concrete slabs were approximately 9 feet square and 6 inches thich. The test procedure was to record the time it took for the jackhammer to cut through the 6-inch section. The results of the tests are summarized in Table 5 for the steel and tungsten alloy pistons. The average cutting time for the steel piston was $11.3 \mathrm{~second}$. whereas the time for the tungsten alloy piston was 8.0 seconds. On average, the cutting time for the tungsten alloy piston was approximately $41 \%$ faster than the steel piston. More test data would have been taken but the last slab had some cracking due to handling and had some steel reinforcement inside, which limited the locations where valid testing could occur. However, the jackhammer with the tungsten alloy piston was then used to break up the useable sections to demonstrate durability. 
Table 5 Jackhammer Tests

\begin{tabular}{|c|c|}
\hline $\begin{array}{c}\text { Stecl piston } \\
\text { cutting time (sec) }\end{array}$ & $\begin{array}{c}\text { Tungsten alioy } \\
\text { piston cutting time } \\
\text { (sec) }\end{array}$ \\
\hline 10.0 & 8.1 \\
\hline 11.0 & 9.1 \\
\hline 12.0 & 8.5 \\
\hline 11.7 & 8.1 \\
\hline 11.8 & 8.2 \\
\hline 11.2 & Average $=8.4$ \\
\hline
\end{tabular}

\subsection{TEST AND ANALYSIS COMPARISON}

Both theory and preliminary experiment suggest that by increasing the density of the piston part on either impact system, the penetration rate is increased, which is the main objective of the tool.

The area ratio of the chipper piston to the bit is 1.5 . The density modulus ratio is 4.0. Using Figure 3.0 the relative velocity ratio of the bit was calculated to be 1.25 for the chipper tool. The measured velocity ratio for the bit with the tungsten piston working against the retainer spring is on the average $34 \%$ higher. The measured penetration rate ratio is inconclusive due to data scatter.

The area ratio of the jackhammer PBS to the bit is 1.0. The equivalent density modules ratio of the tungsten alloy to steel is 2.4. Using Figure 3 the relative velocity ratio of the bit was calculated to be 1.22 . The measured average penetration rate is $41 \%$ faster for the modified PBS tests.

For both cases, the chipper tool and jackhammer, the measured performance for the modified tools was higher than that calculated for the analytical model. The higher measured result may be attributed to increased target force penetration efficiency for the modified tools, uncertainties in conducting the test, or the need to develop a new three component impact model of the penetration process. 
The modified designed piston did not have a signilicant effect on the handling of the jackhammer as a whole, especially since the extra weight of the piston only adds a few pounds to a 90-pound jackhammer. The operator thought there was no significant difference between the

wo jackhammers, but he could feel more shock in his hands when using the modified PBS but it was still comfortable. The sound level was also comparable to a regular jackhammer. The modified chipper was only $4 \mathrm{db}$ higher than the steel piston design.

\subsection{CONCLUSION \& RECOMMENDATION}

The experimental data suggests that the performance improvement in terms of bit velocity or penetration rate is greater than that predicted by a simplified analytical model. The experimental tests had uncertainties in several areas including local material property variations in the target material and operator pressure variations. The material property variations can be reduced by using a well characterized homogenous grout target material. Operator variations can be eliminated by using a mechanical setup similar to the jackhammer system used in Reference 8 . Additional tests should be performed using Du preferably with a nickel coating to control contamination. The best uses or benefits in using DU in impact equipment are most likely in heavy stamping machines or pile drivers because of potential licensing difficulties of radioactive materials. 


\subsection{REFERENCES}

1. Disclosure and Record of Invention, Invention Case No.: IL 9039, "Using the High-Density Hammers to Improve the Performance of Pneumatic and Hydraulic Impact and Tumneling Tools", Ronald Warren Hoard, William Glemn Funkhouser. Milton Dennis Bell . Hector Medecki.

2. Disclosure and Record of Invention. Invention Case No.: IL-10227, "Incorporating Depleted Uranium Material to Improve the Performance of Jack Hammers and Other Pneumatic Impact Tools", Ronald W. Hoard, Larry E. Fischer.

3. Goldsmith. W. (1960): Impact. London: Edward Anold.

4. Lundberg. B. (1981): Microcomputer Simulation of Longitudinal Impact Between Nonuniform Elastic Rods. Int. J. Mechanical Engincering Education 9, 301-315.

5. Lundberg. B. (1982): Microcomputer Simulation of Stress Wave Energy Transfer to Rock in Percussive Drilling. Int. J. Rock Mech. Min. Sci. and Gcomech, Abstr. 19 229-239

6. Pang, S. S. (1986): Investigations of Pneumatic Percussive Processes Involving Rocks PhD. Dissertation. University of California, Berkeley.

7. Pang, S. S., Goldsmith, W. Hood, M. (1989): A Force-Indentation Model for Brittle Rocks. Rock Mech. 22, 127-148.

8. Pang, S. S., Goldsmith, W. (1989): Momentum and Energy Process During Jackhammer, Rock Mech. 22. 205-229. 
